\title{
Mediterranean, vegetarian and vegan diets as practical outtakes of EAS and ACC/AHA recommendations for lowering lipid profile
}

\author{
Anna Wojda ${ }^{1 \otimes}$, Agata Janczy ${ }^{1}$ and Sylwia Małgorzewicz² \\ 1Department of Nutritional Biochemistry, Faculty of Health Sciences, Medical University of Gdansk, Gdańsk, Poland; 2Department of Clinical \\ Nutrition, Faculty of Health Sciences, Medical University of Gdansk, Gdańsk, Poland
}

\begin{abstract}
Reduction of total cholesterol (TC) and LDL fraction (LDL-C) may be beneficial towards decreasing the risk of development of cardiovascular diseases (CVD). First and foremost, before implementing or simultaneously with pharmacological treatment, patients should be informed about lifestyle changes that may be critical to achieving a better lipid profile. Recommendations from ACC/AHA (American College of Cardiology and American Heart Association) and EAS (European Atherosclerosis Society) mainly focus on limitation of saturated fatty acids (SFA) and trans fatty acids (TFA) consumption, but additional support could be considered. This review presents selected guidelines of European scientific societies concerning lipid metabolism disorders. The main aim of this manuscript was to present the guidelines how to provide simple and transparent schemes of management in dyslipidemia therapy. Encouraging patients for increasing the intake of soluble fiber (SF) and phytosterols (PS) may also be promoted for achieving therapeutic goals. In the clinical point of view, restoring an appropriate lipid profile is important because it directly reduces the risk of developing atherosclerotic cardiovascular disease (ASCVD). The EAS and ACC/AHA guidelines introduce several new demands, so far absent from previous recommendations. Mediterranean diet (MD) or vegetarian lifestyles are an example of diet patterns that are deliberated as healthy for cardio-vascular system, since both consist of fresh, unprocessed vegetables and fruits with addition of desirable fats.
\end{abstract}

Key words: cardiovascular diseases, nutrition, lipid profile, cholesterol, prevention

Received: 11 October, 2020; revised: 23 November, 2020; accepted: 02 December, 2020; available on-line: 05 February, 2021

$\square$ e-mail: anna.wojda@gumed.edu.pl

Abbreviations: ACC/AHA, American College of Cardiology and American Heart Association; ASCVD, atherosclerotic cardiovascular disease; CHD, coronary heart disease; CO, coconut oil; CVD, cardiovascular diseases; DF, dietary fiber; EAS, European Atherosclerosis Society; FA, fatty acids; Gl, glycemic index; HDL, high-density lipoprotein; HMG-CoA, 3-hydroxy-3-methylglutaryl-coenzyme A; hsCRP, high sensitivity C-reactive protein; LC-SFA, long chain saturated fatty acids; LDL-C, low-density lipoprotein; LDLR, low density lipoprotein receptor; MC-SFA, medium chain saturated fatty acids; MD, Mediterranean diet; MUFA, monounsaturated fatty acids; PS, phytosterols; PUFA, polyunsaturated fatty acids; SF, soluble fiber; SFA, saturated fatty acids; TC, total cholesterol; TFA, trans fatty acids; TG, triacylglycerides; WHO, World Health Organization

\section{INTRODUCTION}

Cardiovascular diseases (CVD) are the main cause of death worldwide - it is estimated that nearly $45 \%$ of all deaths in European population are caused by them (Michas et al., 2019). CVD include conditions as: coronary heart disease (CHD), vein thrombosis, cerebrovascular disease and other (Michas et al., 2019; Stewart et al., 2017). Most prevalent acute cardiovascular incidents, that may lead to sudden death, include myocardial infarction, stroke, and angina pectoris (Hinton et al., 2018). Widely prevalence of CVD may be related to development of atherosclerosis plaque which is caused by factors that might be specified as unhealthy lifestyle choices (Kilkenny et al., 2017; Eilat-Adar et al., 2013). Excessive body mass and obesity, hypertension, western diet, smoking, stressful life, and limited physical activity may be associated with non-beneficial alterations in lipid profile correlated with higher risk of CVD development (Savji et al., 2013). It seems relevant to put special emphasis on lifestyle changes of patients dealing with diabetes type 2, hypertension, or hyperlipidemia itself (Michas et al., 2019).

European Atherosclerosis Society (EAS) and American College of Cardiology and American Heart Association (ACC/AHA) came up with recommendations for managing lipid profile in terms of primary prevention of CVD (Arnett et al., 2019, Mach et al.,2019). It is noticeable, that some of them were dedicated to lifestyle changes - as one of strategies of avoidance of CVD development, presenting that nutrition and weight management have crucial role in evidence-based medicine. It should be mentioned that majority of their implications have a level of evidence that determines the data collected from randomized clinical trials or meta-analysis. Mostly, for TC and LDL-C reduction it is suggested that diet should deliver trans and saturated fats in limited amount and be rich in dietary fiber. Reduction of alcohol intake may have positive influence in managing triacylglycerides (TG) levels. To achieve an increase in HDL cholesterol levels, physical activity should be maintained (Mach et al., 2019). AHA suggestions are gathered in Table 1 with EAS guidelines.

Similarity between both statements shows that the most crucial for lipid profile control are the quality of fats in diet, weight management and increased physical activity (Mannu et al., 2013; Kelly, 2010). Soluble fraction of fiber and phytosterols are also considered as helpful in goal achievement (Islam et al. 2019; Solà et al., 2010). Mediterranean, vegetarian, and vegan diets are based on vegetables, fruits, nuts, seeds and vegetable oils or lean meat and sea fish (Davis et al., 2015; Misra et al., 2018; Dyett et al., 2014). Those components are sources of unsaturated fats, dietary fiber, and polyphenols, which may be relevant for patients with disturbed lipid profile. 
Table 1. Recommendations from EAS and ACC/AHA (Arnett et al., 2019, Mach et al., 2019).

EAS guidelines
Trans fatty acids and SFA avoidance
Increased consumption of fiber
Increased consumption of food enriched with phytosterols
Introduction of red yeast rice nutraceuticals
Reduction of excessive body weight
Reduction of dietary cholesterol consumption
Increase habitual physical activity
ACC/AHA guidelines
Nutrition pattern increasing intake of vegetables, fruits, legumes nuts, whole grains and fish
Replacement of saturated fat with dietary monounsaturated and polyunsaturated fats
A diet containing reduced amounts of cholesterol and sodium
As a part of healthy diet, it is reasonable to minimize the intake of processed meats, refinied carbohydrates, and sweetened beverages
The intake of trans fats should be avoided

Abbreviation: ACC/AHA, American College of Cardiology and American Heart Association; EAS, European Atherosclerosis Society; SFA, saturated fatty acids.

\section{REDUCTION OF SATURATED FATTY ACID AND TRANS ISOMERS CONSUMPTION}

Guidelines suggest the reduction of SFA to about less than $7 \%$ of consumed energy and almost total exclusion of TFA (Arnett et al., 2019, Mach et al., 2019). The most common SFAs in a typical omnivore diet are those with at least 12 atoms of carbon, described as long chain SFA (LC-SFA) (O'Sullivan et al., 2013). Nutrition pattern based on animal derived products (meat, milk and dairy products, butter, lard) and with higher consumption of highly processed food may be detrimental for maintaining proper cardiovascular health (O’Sullivan et al., 2013). It may be suggested that plant-based diet may be more beneficial for reducing CVD risk, however LC-SFA can be also found in plant delivered oils such as coconut (USDA, 2019), palm (Forouhi et al., 2018) and cocoa (Nettleton et al., 2017).

Based on widespread availability of SFA, specific education for patients is needed - information about sources of SFA and possible nutrition exchangers should be provided. The recommendations suggest an increased intake of MUFA and PUFAs towards a reduction in the consumption of SFA and TFA (Arnett et al., 2019; Mach et al., 2019). MUFA and PUFA can be found in vegetable oils, nuts, seeds, avocado, and sea fish. However, it is observed that consumption of SFA is still increased and should be limited (USDA, 2019). It should be mentioned that popular fats used in many cuisines (butter, coconut oil) may not be beneficial for patients with higher risk of developing CVD.

Worldwide growth in popularity of coconut oil (CO) was observed in recent years (Eyres et al., 2016). CO was named as one of the superfoods, meaning it is a food product beneficial to human health, and it is relatively cheap, which may have contributed to increased interests in $\mathrm{CO}$. Due to FA content, $\mathrm{CO}$ may be considered as MC-SFA (Medium Chain SFA) food source (USDA, 2019). MC-SFA are studied as one of strategies for Alzheimer's disease prevention (Courchesne-Loyer et al., 2017), support of traditional therapy in hepatic disease and possible support in body mass reduction (Kasai et al., 2003). In comparison to LC-SFA which are bonded into chylomicrons and absorbed via lymphatic system in small intestine, medium chain fatty acids are suddenly absorbed and transported to liver via portal venous system, providing quicker energy supply (Iggman \& Risérus, 2011; Schönfeld et al., 2016; Flock et al., 2013).

However, it should be emphasized that coconut oil FA composition is far from being MC-SFA source. CO contains lauric acid, which may be considered as MCSFA, since it is absorbed rapidly and transferred to liver, nonetheless lauric acid is included into SFA group that have hypercholesteremic effect (Oliveira-de-Lira et al., 2018). Other SFA that may influence increase of TC and LDL-C concentrations are myristic and palmitic acids, which are also present in CO composition (Hunter et al., 2010).

Interestingly, several studies suggest that native inhabitants of regions of coconut palm cultivation, present overall good cardiovascular outcomes and those may relate to higher consumption of coconut oil (DiBello et al., 2009). These studies and the potentially high MCSFA content contributed to the growing interest in coconut oil, however comparing to the usual western diet it may have more detrimental outcome. Described native populations declare nutrition pattern based on fresh vegetables, fruits, nuts with the reduction of animal derived products. Increased intake of dietary fiber was also observed (DiBello et al., 2009). Processed food such as meals ready to eat or semi-finished products traditionally do not occur in their nutrition. It is noticeable that in those studies, high daily intake of fats was observed, which varied from 26-49\% delivered energy, however majority of those derived from plant or fish (DiBello et al., 2009). It was observed that the consumption of fruit and vegetables exceeded the recommended 5 servings per day, which may implicate that dietary fiber intake also surpassed advised 30-45 g daily (DiBello et al., 2009; Duthie et al., 2018). Studies held in America and European countries show that there is no conclusion if coconut oil may be beneficial for maintaining or promoting good cardiovascular health (Oliveira-de-Lira et al., 2018; Maki et al., 2018; Vijayakumar et al., 2016; Cardoso et al., 2015; Harris et al., 2017). Nonetheless, it is safe to assume that products rich in MUFA and PUFA will have more profitable influence on overall health, than dietary fats rich in SFA.

Butter is another popular food source of SFA and cholesterol. Debate whether milk fat may be present in a healthy diet is still ongoing - some scientific reports suggest that high content of SFA may be unbeneficial for subjects with elevated lipid profile (Khaw et al., 2018; Hjerpsted et al., 2011; Von Ruesten et al., 2013), however some studies propose that dairy products and dairy fat may decrease the risk of CVD (Crichton \& Alkerwi, 2014; Lordan et al., 2018; Drouin-Chartier et al., 2016). Furthermore, butter as an animal derived product contains dietary cholesterol and its higher consumption may lead to an increase in TC and LDL-C levels (Zhong et 
al., 2019; Okami et al., 2019). To summarize this discussion, if butter has more beneficial or detrimental influence on cardiovascular health, one of meta-analysis focusing on butter intake and all-cause deaths $\mathrm{RR}=1.01$ $(95 \% \quad \mathrm{CI}=1.00,1.03)$, atherosclerosis heart incidents $\mathrm{RR}=0.99(95 \% \mathrm{CI}=0.96,1.03)$ and heart attacks $\mathrm{RR}=1.01$ $(95 \% \mathrm{CI}=0.98,1.03)$ and no strong correlation was observed between these results (Pimpin et al., 2016). Further research is needed, especially among subjects from groups of higher CVD risk with different nutrition patterns. At the same time patients should be encouraged to decrease their intake of full-fat dairy products towards products with lowered fat content as it is safe to assume that butter can be replaced with vegetable oil with high content of MUFA or PUFA (e.g., olive or canola oil).

Another crucial element of maintaining correct cholesterol levels is consumption of trans isomers of polyunsaturated fatty acids. It is suggested that TFA should be completely limited in daily consumption to the point when they deliver less than 1\% of whole energy (Mannu et al., 2013; Kelly, 2010). In nature, TFA occur in milk and meat of ruminants in limited amount. Due to technological development TFA are widely present in margarines, highly processed food, sweets, savory snacks and in a few vegetable oils (Ahmed et al., 2018; Gupta et al., 2019; Ford et al., 2016). Margarines are often chosen and promoted as a healthier substitute for butter, since they do not contain dietary cholesterol and may be fortified with beneficial plant sterols, however some of them may contain trans FA (Gagliardi et al., 2010). It is observed that higher intake of TFA may influence higher LDL serum concentrations (Grabovac et al., 2018; Li et al., 2017), thus World Health Organization (WHO) suggest replacing them with cis isomers delivered from MUFA and PUFA or at the same time with complex carbohydrates towards beneficial increase of HDL-C with simultaneous decrease of TC and LDL-C levels (Riccardi et al., 2016)

For better outcomes in lipid control, vegetarian or vegan diets may be suggested. It is observed that lifestyles patterns based on increased plant products intake and exclusion of products of animal origin are correlated with improved lipid profile (Viguiliouk et al., 2019; Matsumoto et al., 2019). Undoubtedly, those changes should apply to unprocessed products, free from TFA or SFA.

\section{INTRODUCTION OF PLANT STEROLS INTO DAILY DIET}

Except SFA and TFA content in ingested diet, consumption of dietary cholesterol may further be essential in human cholesterol metabolism (Zhong et al., 2019; Okami et al., 2019). The decrease in intestinal absorption leads to a shortage of cholesterol, encouraging internal mechanisms towards biosynthesis and an increase in activity of the LDL receptor (LDLR), to secure the body's requirements (Kapourchali et al., 2015). As a consequence, reducing the cholesterol pool through limited consumption and increased receptor activity may lead to a reduction in blood TC concentrations (Alphonse et al., 2015).

In practice, to obtain the state of cholesterol shortage, increased consumption of PS may be recommended (Ferguson et al., 2018). Plant sterols or phytosterols have similar chemical structure as cholesterol, however they are mostly present in plant sources. That resemblance makes PS more susceptible to be absorbed in intestine and leads to decreased availability of dietary cholesterol by removing it with the feces (Sanclemente et al., 2012).
As one of lifestyle changes and non-pharmacological approach dose of 1,3-2 g PS per day may be significant for lowering cholesterol concentrations (Ottestad et al., 2013). In food sources, PS are found in fresh fruits, vegetables and vegetable oils, seeds, nuts, and legumes but it's observed that even a large consumption of these products may not be sufficient to meet the cholesterol lowering needs (Sanclemente et al., 2012). Otherwise, diet rich in natural sources of PS may be adequate for preventive purposes for general population, based on observations of residents of European countries (Kapourchali et al., 2015). For the best possible cholesterol reduction, PS dietary supplements or products fortified with PS may be considered (Malina et al., 2015). Margarines enriched with PS are popular among patients with hyperlipidemia because they replace butter, and their plant sterol content is high enough to be sufficient for hypolipidemic outcomes (Eady et al., 2011). It is also a beneficial solution for hypercholesterolemic patients to exchange butter with margarine, because the second does not include dietary cholesterol. However, it is crucial to educate about possibility of choosing products with higher TFA content.

\section{INCREASED CONSUMPTION OF SOLUBLE FIBER}

Dietary fiber (DF) is often mentioned as the basis of proper nutrition. DF ensures feeling of satiety after a meal, as a result of swelling capacities, have an influence on digestion with maintaining regular peristaltic movements and can be beneficial for gut microbiome (Maćkowiak et al., 2016). It is recommended to consume about 25-40 g of fiber daily, including 7-13 g of its soluble fraction (Maćkowiak et al., 2016). Food products with higher content of fiber have also lower glycemic index than processed or refined products (Dhingra et al., 2012). Those properties may be beneficial for patients with diabetes or those who have difficulty feeling full after a meal, and fiber may be crucial in the diet of hypercholesterolemic subjects.

Cholesterol lowering properties of fiber are presumably achieved by two mechanisms:

- products with low GI reduce the release of insulin from the pancreas in contrast to food with high GI (1)

- and soluble fraction of fiber contributes to increasing hepatic bile synthesis (2) (Gunness \& Gidley, 2010).

Foremost, cholesterol biosynthesis is based on alteration of 3-hydroxy-3-methylglutaryl-CoA to mevalonate (Cerqueira et al., 2016). For this reaction HMG-CoA reductase is needed, as an enzyme regulating the whole process. HMG-CoA is coordinated by few hormones e.g., insulin and glucagon with antagonistic effect (Burg \& Espenshade, 2011). Usually, glucagon is released in the situation of decreased blood glucose levels, which tends to be in states of fasting, during low carbohydrate diet and during intense physical activity. Contrarily, insulin is synthesized when glucose levels are increasing e.g., after meals rich in carbohydrates and in subjects with insulin resistance (Burg \& Espenshade, 2011). Glucagon endorse HMG-CoA reductase inactivation with a cascade of phosphorylation, and insulin is needed for a reverse reaction - dephosphorylation, which activate enzymes and can initiate cholesterol synthesis (Cerqueira et al., 2016). Increased consumption of soluble fiber may contribute to binding with cholesterol particles in the lumen of the small intestine, which inhibits cholesterol absorption. Moreover, SF influences extraction of bile acids 


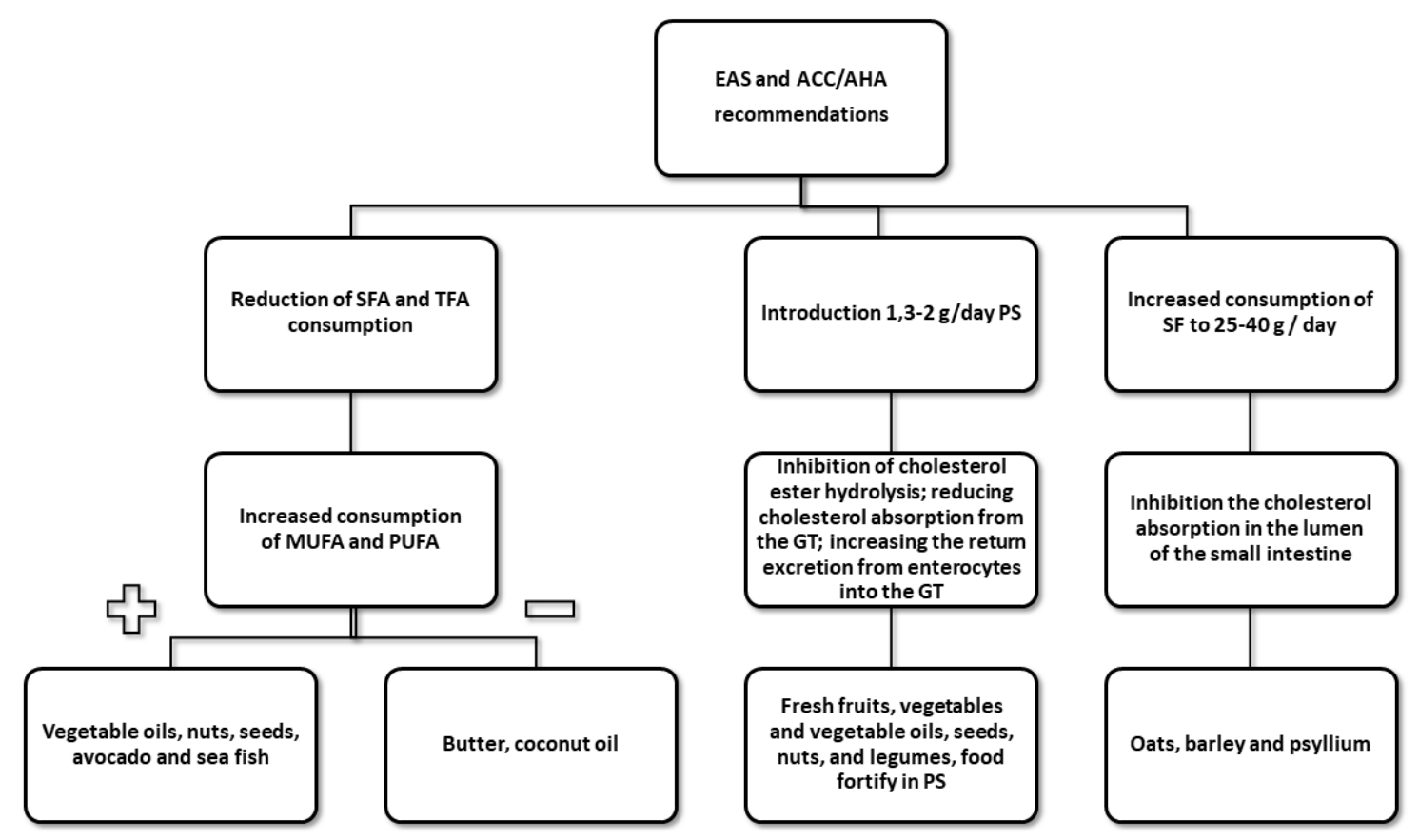

Figure 1. Recommended products to improve lipid profile according to the EAS and ACC/AHA.

with fecal matter, inducing cholesterol uptake by liver towards bile synthesis (McRae, 2017).

Soluble fiber is widely found in oats, barley and psyllium (Maćkowiak et al., 2016). It is suggested that SF may be beneficial for patients not yet undergoing pharmacological treatment, although increased consumption of SF is considered safe when drugs are already taken (Solà et al., 2010). However, SFs are especially beneficial for patients with cholesterol-lowering drug side effects and low tolerance to them - studies have shown that SF decrease TC and LDL-C concentrations about 2 to $24 \%$ and 2 to 20\% respectively (Brum et al., 2018). Increased consumption of fiber has one preeminent drawback - a rapid change in the amount of consumed fiber in the diet can contribute to the appearance of gastrointestinal discomfort such as diarrhea, flatulence or gases, but those complaints disappear after adjusting to higher doses of DF (Zhang et al., 2020).

\section{BODY MASS REDUCTION}

Excessive body mass is correlated with higher risk of civilization diseases e.g., diabetes type 2, cancers and CVD ( $\mathrm{Na}$ et al., 2011). People with redundant fat content are more susceptible to develop higher TC and LDL-C concentrations, as a consequences of unhealthy lifestyle patterns such as western diet and limited physical activity (Kopp, 2019). EAS guidelines suggest that weight loss of $10 \mathrm{~kg}$ may decrease LDL-C levels by $8 \mathrm{mg} / \mathrm{dl}$ $(0.2 \mathrm{mmol} / \mathrm{l})$ and that may be relevant as an additional support in managing lipid profile (Mach et al., 2019). However, reduction of $10 \mathrm{~kg}$ for some subjects may be not possible, e.g., for patients with familial hypercholesterolemia with BMI in normal ranges, that is why body mass reduction should not be the only approach for lipid control and rather a supportive approach for other possibilities. Several studies compared influence of various physical activity levels and diet (especially caloric deficit) on body mass reduction; therefore, improving lipid profile (Brouwers et al., 2016; Igarashi \& Nogami, 2019;
Mann et al. 2014; Romero-Moraleda et al., 2015). In conclusion, patients, particularly those with increased body weight, should be encouraged to exercise regularly and rethink their eating habits to maintain the goal of reducing excess fat. Reduction of fat mass may lead to a decrease of TAG quantity, therefore improving LDL-C concentrations (Theodore et al., 2007). What is more, obesity may lead to insulin resistance and an increased release of insulin from the pancreas, which is necessary in cholesterol synthesis (Burg \& Espenshade, 2011). High quality diet with limited amount of processed products and ready to eat meals may be beneficial in maintaining correct body mass or reducing body mass, that is why nutrition plans based on fresh vegetables, fruits and wholegrain products may be helpful solutions for patients.

\section{MEDITERRANEAN, VEGETARIAN AND VEGAN DIETS AS CARDIOVASCULAR FRIENDLY LIFESTYLE HABITS}

Recommendations from AHA and EAS towards lifestyle changes mainly suggest high quality diet what may be described as a reduction of TFA, limitation of SFA consumption in favor of MUFA and PUFA content (Fig. 1) (Arnett et al., 2019; Mach et al., 2019). Inclusion of phytosterols and soluble fiber may be helpful in reduction of serum cholesterol concentrations, as well as restraint of dietary cholesterol intake. Weight reduction approaches should be considered for obese and overweight patients- introducing caloric restriction and regular exercise for improving lipid profile and reducing other CVD risk factors (Arnett et al., 2019; Mach et al., 2019). From nutritional perspective Mediterranean, vegetarian or vegan lifestyles may be a practical solution for implementing those guidelines.

Mediterranean diet (MD) is mostly based on fresh and seasonal fruits, vegetables, fish, olive oil and whole wheat products (Trichopoulou et al., 2014). Theoretically, $\mathrm{MD}$ is composed from fresh, non-processed meals with variety of nutritional, high quality products (Trichopoulou et al., 2014). It was observed that nations located 
near Mediterranean Sea have lower risk of developing CVD and better overall cardiovascular outcomes (e.g., lipid profile) than residents of different European countries (Knoops et al., 2004). Since influence of MD on overall health outcome was observed, food pyramids were proposed to make recommendations simple enough to implement without additional explanation (Vitiello et al., 2016; D’Alessandro et al., 2019).

Few studies analyzed influence of some food products - patients were encouraged to consume olive oil (11 per week per household, at the minimum of 4 tablespoons of oil for each person), mixed nuts (walnuts, hazelnuts and almonds; 30 grams daily) or to maintain healthy, balanced diet (Estruch et al., 2013). After reaching median of 4,8 years, the study ended with observations that increasing consumption of olive oil to 10 grams per day was correlated with a decrease of $30 \%$ of CVD relative risk among patients from high-risk groups. Similar outcomes were observed in a group that was consuming 30 grams of nuts per day (Estruch et al., 2013).

Possible correlation between quality of consumed fats and risk of developing CVD was also observed (GuaschFerré et al., 2015). Long-term research of 7038 participants of PREDIMED study has shown that incorporating more MUFA into diet may result in lowering risk of CVD and may be especially beneficial when those are used as a substitute of SFA and TFA. It was noted that subjects with higher intake of those FA had $81 \%$ and $67 \%$ chances of developing CVD. There is no doubt, that both fatty acids are more detrimental for cardiovascular health and limited consumption should be included into healthy nutritional habits. PREDIMED study also shows that changes are relatively accessible to implement, with choosing olive oil instead of other vegetable oils or adding a portion of nuts every day. It was also noted that quality of consumed fat is more important than quantity, since $\mathrm{MD}$ is based in products with high fat content and may exceed recommended $20-30 \%$ of delivered energy (Guasch-Ferré et al., 2015).

Nuts and vegetable oils, especially those derived from olive and canola, are great sources of PUFA n-3, which higher intake may be beneficial for increasing HDL$\mathrm{C}$ concentrations and reducing LDL-C and TC levels (Leslie et al., 2015). PUFA n-3 are also present in sea fish, specifically in those with higher fat content such as salmon, tuna, herring or mackerel (Shahidi \& Ambigaipalan, 2018). People living near Mediterranean Sea, take advantage of the benefits of being close to the sea and exchange meat intake for fish consumption (Trichopoulou et al., 2014). Moreover, due to increased consumption of vegetables, fruits and whole grain products, dietary fiber and phytosterols are introduced to daily diet, which may be another crucial cardioprotective effect of MD (Shahidi \& Ambigaipalan, 2018).

Vegetarian or vegan diets are mostly plant based nutrition patterns, with exception of animal derived products such as dairy, eggs or butter (Nebl et al., 2019). Both of them may be beneficial for patients with higher TC serum levels, since those do not provide any (or in limited amount) dietary cholesterol (Zhong et al., 2019; Okami et al., 2019). Those should be considered for subjects without lipid lowering drugs, specifically for patients experiencing side effects after taking medication (Huang et al., 2014). Additionally, vegetarian diets are a rich source of nutraceuticals delivered in vegetables, fruits and nuts, which may be lacking in omnivore diet (Clarys et al., 2014). Plant sterols, polyphenols such as resveratrol and other may be beneficial for patients with dyslipidemia or hypertension (Sosnowska et al., 2017). Due to an in- creased consumption of fruits, vegetables and whole grain products higher intake of fiber, with its soluble fraction, may be observed among subjects consuming vegan or vegetarian diet (Tong et al., 2019). It is safe to assume that vegetarian or vegan diets are most profitable for maintaining a lipid profile in desirable ranges, since both of them are rich in phytosterols, fiber and are lacking in dietary cholesterol. Moreover, plant-based diets are proved to have beneficial influence on sudden cardiac incidents occurrence compared to omnivore provisions (Rogerson, 2017). However, those nutritional patterns are not safe from SFA and TFA, especially when exotic oils (such as coconut or palm oils) or ready to eat meals are used (Mani \& Kurpad, 2016). Education about possible food sources of those fatty acids may be relevant to introduce vegetarianism/veganism for heart protective outcomes.

The presented dietary regimens have many similarities - increased dietary fiber intake, decreased consumption of SFA and TFA, and they are rich in nutritional food sources. Whole grain products, fresh and nonprocessed fruits and vegetables are the basis of those nutritional plans. It should be highlighted that fiber may be beneficial especially for subjects with excessive body weight, which is one of the CVD risk factors. It was observed that overweight and obese women after 10 weeks of diet with increased amount of dietary fiber have better cardiovascular outcomes such as lower LDL and TG levels with significantly noticeable weight loss (Fatahi et al., 2018). Mean intake of DF was about 39 $\mathrm{g}$ per day, which exceeded recommended $25 \mathrm{~g}$ daily. In this research weight loss may be a major contributor to improving lipid profile (LDL $110 \mathrm{mg} / \mathrm{dl}$ vs $99 \mathrm{mg}$ / $\mathrm{dl}$ and $114 \mathrm{mg} / \mathrm{dl}$ vs $94 \mathrm{mg} / \mathrm{dl}$ ), however incorporating DF could be beneficial for hormonal balance especially insulin secretion after a meal which may result in preventing insulin resistance. Another research showed that increased consumption of DF can be related with lowering blood pressure, which is another risk factor of premature death from CVD (Kirwan et al., 2016).

Prospectively, diet interventions could be matched to the expected results e.g., lowering different fractions of lipid profile or markers of inflammation. It was observed that vegetarian diet may be more effective in lowering total and LDL cholesterol, while Mediterranean diet is efficient with impact on TG levels, although both of these nutritional patterns are considered good for cardiovascular health (Sofi et al., 2018). Another research has shown that vegan diet may be considered for patients at high risk of developing CVD with presence of atherosclerosis plaque (Shah et al., 2018). It is well known that major risk factor of CVD is atherosclerosis development, which may be caused by prolonged inflammation (Shah et al., 2018). It is observed that subjects with coronary heart disease have increased levels of inflammation markers such as hsCRP (high sensitivity C-reactive protein) (Geovanini \& Libby, 2018; Abolhasani et al., 2019). Research conducted on patients with CAD has shown that those who were on vegan diet, had about $38 \%$ lower hsCRP levels than those on recommended by AHA/ACC nutrition plan (Shah et al., 2018). It was observed that vegan group had higher intake of fiber, carbohydrates and lower of SFA, TFA and cholesterol, which may suggest that the main advantage of veganism towards anti-inflammatory effect is fiber and complex carbohydrate content (Ma \& Li., 2018). Moreover, $\mathrm{DF}$ is needed for the proper development of the human microbiota, one of the components of the immune sys- 
tem, whose role in CVD prevention need further studies (Makki et al., 2018; Visioli et al., 2019).

Major difference between MD and VD is the presence of animal food products such as meat, milk and fat, however in comparison to western diet, both nutritional plans assume limiting intake of SFA, TFA and cholesterol. It may suggest that the biggest cardioprotective agents in MD and VD are high content of MUFAs and PUFAs, complex carbohydrates, dietary fiber and nutraceuticals present in fruits, vegetables, nuts and seeds. Besides plant sterols, some of them may be hydroxytyrosol, one of the phenols from olive oil, or soy derived products - such as lecithin or isoflavones (Visioli \& Poli, 2019; Poli et al., 2018). It is observed that those substances can be responsible for lowering LDL cholesterol as well as anti-inflammatory actions (Visioli \& Poli, 2019; Poli et al., 2018). However, there is no relevant data showing if increased consumption of nutraceuticals from diet may be as beneficial as supplementation.

\section{CONCLUSION}

Recommendations for managing dyslipidemias and reducing CVD risk are mostly helpful for medical professionals such as doctors, nurses or dietitians, nonetheless they may be incomprehensible for patients. Education about lifestyle changes may be helpful for implementing those guidelines in practice. Nutritional knowledge should be taught and explained due to growing popularity of non-medical and not evidence-based information. Superfood status of some products should also be taken with a grain of salt, since some of them, despite general opinion may not be suitable for subjects with higher CVD risk.

It is also crucial to encourage patients to increase the consumption of fruits and vegetables due to naturally occurring phytosterols and dietary fiber. Supplementation with plant sterols should also be considered to maximize traditional pharmacology treatment. Advice about the sources of soluble fiber should be provided, since some patients may choose supplements or plant extract for achieving visible decrease in TC and LDL-C concentrations. It should be emphasized that nutritional and lifestyle changes will be more beneficial than using supplements while maintaining unhealthy habits.

In order to make those changes more accessible, Mediterranean, vegetarian or vegan diets may be recommended. All of them have scientific background for decreasing TC and LDL-C levels, however diet plan should be chosen for patients individually, including dietary preferences, possibilities, and health limitations.

\section{Conflicts of Interest}

The authors declare no conflict of interest.

\section{REFERENCES}

Abolhasani S, Shahbazloo SV, Saadati HM, Mahmoodi N, Khanbabaei N (2019) Evaluation of serum levels of inflammation, fibrinolysis and oxidative stress markers in coronary artery disease prediction: a cross-sectional study. Arq Bras Cardiol 113: 667-674. https://doi. org/10.5935/abc.20190159

Ahmed HS, Kharroubi W, Kaoubaa N, Zarrouk A, Batbout F, Gamra H, Najjar MF, Lizard G, Hininger-Favier I, Hammamil M (2018) Correlation of trans fatty acids with the severity of coronary artery disease lesions. Lipids Health Dis 17: 52. https://doi.org/10.1186/ s12944-018-0699-3

Alphonse PAS, Jones PJH (2015) Revisiting human cholesterol synthesis and absorption: the reciprocity paradigm and its key regulators. Lipids 51: 519-536. https://doi.org/10.1007/s11745-015-4096-7
Arnett DK, Blumenthal RS, Albert MA, Buroker AB, Goldberger ZD, Hahn EJ, Himmelfarb CD, Khera A, Lloyd-Jones D, McEvoy JW, Michos ED, Miedema MD, Muñoz D, Smith SC Jr, Virani SS, Williams KA Sr, Yeboah J, Ziaeian B. 2019 ACC/AHA Guideline on the Primary Prevention of Cardiovascular Disease (2019) A Report of the American College of Cardiology/American Heart Association Task Force on Clinical Practice Guidelines. 140: e596-e646. https://doi.org/10.1161/CIR.0000000000000678

Brouwers B, Hesselink MK, Schrauwen P, Schrauwen-Hinderling VB (2016) Effects of exercise training on intrahepatic lipid content in humans. Diabetologia 59: 2068-2079. https://doi.org/10.1007/ s00125-016-4037-x

Brum J, Ramsey D, McRorie J, Bauer B, Kopecky SL (2018) Metaanalysis of usefulness of psyllium fiber as adjuvant antilipid therapy to enhance cholesterol lowering efficacy of statins. Am J Cardiol 122: 1169-1174. https://doi.org/10.1016/j.amjcard.2018.06.040

Burg JS, Espenshade PJ (2011) Regulation of HMG-CoA reductase in mammals and yeast. Prog Lipid Res 50: 403-410. https://doi. org/10.1016/j.plipres.2011.07.002

Cardoso DA, Moreira AS, de Oliveira GM, Raggio Luiz R, Rosa G (2015) A coconut extra virgin oil-rich diet increases HDL cholesterol and decreases waist circumference and body mass in coronary artery disease patients. Nutr Hosp 32: 2144-2152. https://doi. org/10.3305/nh.2015.32.5.9642

Cerqueira NMFSA, Oliveira EF, Gesto DS, Santos-Martins D, Moreira C, Moorthy HN, Ramos MJ, Fernandes PA (2016) Cholesterol biosynthesis: a mechanistic overview. Biochemistry 55: 5483-5506. https://doi.org/10.1021/acs.biochem.6b00342

Clarys P, Deliens T, Huybrechts I, Deriemaeker P, Vanaelst B, De Keyzer W, Hebbelinck M, Mullie P (2014) Comparison of nutritional quality of the vegan, vegetarian, semi-vegetarian, pesco-vegetarian and omnivorous diet. Nutrients 6: 1318-1332. https://doi. org/10.3390/nu6031318

Courchesne-Loyer A, Lowry CM, St-Pierre V, Vandenberghe C, Fortier M, Castellano CM, Wagner JR, Cunnane SC (2017) Emulsification increases the acute ketogenic effect and bioavailability of mediumchain triglycerides in humans: protein, carbohydrate, and fat metabolism. Curr Develop Nutrition 1: e000356. https://doi.org/10.3945/ cdn.117.000851

Crichton GE, Alkerwi A (2014) Dairy food intake is positively associated with cardiovascular health: findings from Observation of Cardiovascular Risk Factors in Luxembourg study. Nutr Res 34: 10361044. https://doi.org/10.1016/j.nutres.2014.04.002

D’Alessandro A, Lampignano L, De Pergola G (2019) Mediterranean diet pyramid: a proposal for italian people. a systematic review of prospective studies to derive serving sizes. Nutrients 11: 1296. https://doi.org/10.3390/nu11061296

Davis C, Bryan J, Hodgson J, Murphy K (2015) Definition of the mediterranean diet; a literature review. Nutrients 7: 9139-9153. https:// doi.org/10.3390/nu7115459

Dhingra D, Michael M, Rajput H, Patil RT (2012) Dietary fibre in foods: a review. J Food Sci Technol 49: 255-266. https://doi. org/10.1007/s13197-011-0365-5

DiBello JR, McGarvey ST, Kraft P, Goldberg R, Campos H, Quested C, Laumoli TS, Baylin A (2009) Dietary patterns are associated with metabolic syndrome in adult Samoans. I Nutr 139: 1933-1943. https://doi.org/10.3945/jn.109.107888.

Drouin-Chartier JP, Côté JA, Labonté MÈ, Brassard D, Tessier-Grenier M, Desroches S, Couture P, Lamarche P (2016) Comprehensive review of the impact of dairy foods and dairy fat on cardiometabolic risk. Adv Nutr 7: 1041-1051. https://doi.org/10.3945/ an.115.011619

Duthie SJ, Duthie GG, Russell WR, Kyle JAM, Macdiarmid JT, Rungapamestry V, Stephen S, Megias-Baeza C, Kaniewska JJ, Shaw L, Milne L, Bremner D, Ross K, Morrice P, Pirie LP, Horgan G, Bestwick CS (2018) Effect of increasing fruit and vegetable intake by dietary intervention on nutritional biomarkers and attitudes to dietary change: a randomised trial. Eur J Nutr 57: 1855-1872. https://doi. org/10.1007/s00394-017-1469-0

Dyett P, Rajaram S, Haddad EH, Sabate J (2014) Evaluation of a validated food frequency questionnaire for self-defined vegans in the United States. Nutrients 6: 2523-2539. https://doi.org/10.3390/ nu6072523

Eady, S, Wallace A, Willis J, Scott R, Frampton C (2011) Consumption of a plant sterol-based spread derived from rice bran oil is effective at reducing plasma lipid levels in mildly hypercholesterolaemic individuals. Brit J Nutr 105: 1808-1818. https://doi.org/10.1017/ s0007114510005519

Eilat-Adar S, Sinai T, Yosefy C, Henkin Y (2013) Nutritional recommendations for cardiovascular disease prevention. Nutrients 5: 36463683. https://doi.org/10.3390/nu5093646

Estruch R, Ros E, Salas-Salvado J, Covas MI, Corella D, Arós F, Gómez-Gracia E, Ruiz-Gutiérrez V, Fiol M, Lapetra J, LamuelaRaventos RM, Serra-Majem L, Pintó X, Basora J, Muñoz MA, Sorlí JV, Martínez JA (2013) Primary prevention of cardiovascular disease 
with a Mediterranean diet. N Engl J Med 368: 12791290. https:// doi.org/10.1056/NEJMoa1200303

Eyres L, Eyres MF, Chisholm A, Brown RC (2016) Coconut oil consumption and cardiovascular risk factors in humans. Nutr Rev 74: 267-280. https://doi.org/110.1093/nutrit/nuw002

Fatahi S, Daneshzad E, Kord-Varkaneh H, Bellissimo N, Brett NR, Azadbakht L (2018) Impact of diets rich in whole grains and fruits and vegetables on cardiovascular risk factors in overweight and obese women: a randomized clinical feeding trial. I Am Coll Nutr. 37: 568-577. https://doi.org/10.1080/07315724.2018.1444520

Ferguson JJA, Stojanovski E, MacDonald-Wicks L, Garg ML (2018) Curcumin potentiates cholesterol-lowering effects of phytosterols in hypercholesterolaemic individuals. A randomised controlled trial. Metabolism 82: 22-35. https://doi.org/10.1016/j.metabol.2017.12.009

Flock MR, Kris-Etherton PM (2013) Diverse physiological effects of long-chain saturated fatty acids: implications for cardiovascular disease. Curr Opin Clin Nutr 16: 133-140. https://doi.org/10.1097/ MCO.0b013e328359e6ac

Ford PA, Jaceldo-Siegl K, Lee JW, Tonstad S (2016) Trans fatty acid intake is related to emotional affect in the Adventist Health Study-2. Nutr Res 36: 509-517. https://doi.org/10.1016/j.nutres.2016.01.005

Forouhi NG, Krauss RM, Taubes G, Willett W (2018) Dietary fat and cardiometabolic health: evidence, controversies, and consensus for guidance. BMJ 361: k2139. https://doi.org/10.1136/bmj.k2139

Gagliardi AC, Maranhão RC, de Sousa HP, Schaefer EJ, Santos RD (2010) Effects of margarines and butter consumption on lipid profiles, inflammation markers and lipid transfer to HDL particles in free-living subjects with the metabolic syndrome. Eur J Clin Nutr 64: 1141-1149. https://doi.org/10.1038/ejcn.2010.122

Geovanini GR, Libby P (2018) Atherosclerosis and inflammation: overview and updates. Clin Sci (Lond) 132: 1243-1252. https://doi. org/10.1042/CS20180306

Grabovac I, Hochfellner L, Rieger M, Jewell J, Snell A, Weber A, Stüger HP, Schindler KE, Mikkelsen B, Dorner TE (2018) Impact of Austria's 2009 trans fatty acids regulation on all-cause, cardiovascular and coronary heart disease mortality. Eur I Public Health 28 : 4-9. https://doi.org/10.1093/eurpub/cky147

Guasch-Ferré M, Babio N, Martínez-González MA, Corella D, Ros E, Martín-Peláez S, Estruch R, Arós F, Gómez-Gracia E, Fiol M, Santos-Lozano JM, Serra-Majem L, Bulló M, Toledo E, Barragán R, Fitó M, Gea A, Salas-Salvadó J (2015) Dietary fat intake and risk of cardiovascular disease and all-cause mortality in a population at high risk of cardiovascular disease. Am J Clin Nutr 102: 1563-1573. https://doi.org/10.3945/ajcn.115.116046

Gunness P, Gidley MJ (2010) Mechanisms underlying the cholesterollowering properties of soluble dietary fibre polysaccharides. Food Funct 1: 149-155. https://doi.org/10.1039/c0fo00080a

Gupta R, Abraham RA, Kondal D, Dhatwalia S, Jeemon P, Reddy KS, Prabhakaran D, Ramakrishnan L (2019) Association of trans fatty acids with lipids and other cardiovascular risk factors in an Indian industrial population. BMC Res Notes 12: 342. https://doi. org/10.1186/s13104-019-4352-7

Harris M, Hutchins A, Fryda L (2017) The impact of virgin coconut oil and high-oleic safflower oil on body composition, lipids, and inflammatory markers in postmenopausal women. I Med Food 20 345-351. https://doi.org/10.1089/jmf.2016.0114

Hinton W, McGovern A, Coyle R, Han TS, Sharma P, Correa A, Ferreira F, De Lusignan S (2018) Incidence and prevalence of cardiovascular disease in English primary care: a cross-sectional and follow-up study of the Royal College of General Practitioners (RCGP) Research and Surveillance Centre (RSC). BMJ Open 8: e020282. http://dx.doi.org/10.1136/bmjopen-2017-020282

Hjerpsted J, Leedo E, Tholstrup T (2011) Cheese intake in large amounts lowers LDL-cholesterol concentrations compared with butter intake of equal fat content. Am J Clin Nutr 94: 1479-1484. https://doi.org/10.3945/ajcn.111.022426

Huang YW, Jian ZH, Chang HC, Nfor ON, Ko PC, Lung CC, Lin LY, Ho CC, Chiang YC, Liaw YP (2014) Vegan diet and blood lipid profiles: a cross-sectional study of pre and postmenopausal women. BMC Womens Health 14: 55. https://doi.org/10.1186/14726874-14-55

Hunter JE, Zhang J, Kris-Etherton PM (2010) Cardiovascular disease risk of dietary stearic acid compared with trans, other saturated, and unsaturated fatty acids: a systematic review. Am J Clin Nutr 91: 46-63. https://doi.org/10.3945/ajcn.2009.27661

Igarashi Y, Nogami Y (2019) Response of Lipids and Lipoproteins to Regular Aquatic Endurance Exercise: A Meta-Analysis of Randomized Controlled Trials. J Atheroscler Thromb 26: 14-30. https:// doi.org/10.5551/jat.42937

Iggman D, Risérus U (2011) Role of different dietary saturated fatty acids for cardiometabolic risk. Clin Lipidol 6: 209-223.

Islam M A, Amin MN, Siddiqui SA, Hossain MP, Sultana F, Kabir MR (2019) Trans fatty acids and lipid profile: A serious risk factor to cardiovascular disease, cancer and diabetes. Diabetes Metab Syndr 3: 1643-1647. https://doi.org/10.1016/j.dsx.2019.03.033
Kapourchali FR, Surendiran G, Goulet A, Moghadasian MH (2015) The role of dietary cholesterol in lipoprotein metabolism and related metabolic abnormalities: a mini review. Crit Rev Food Sci Nutr 56: 2408-2415. https://doi.org/10.1080/10408398.2013.842887

Kasai M, Nosaka N, Maki H, Negishi S, Aoyama T, Nakamura M, Suzuki Y, Tsuji H, Uto H, Okazaki M, Kondo K (2003) Effect of dietary medium- and long-chain triacylglycerols (MLCT) on accumulation of body fat in healthy humans. Asia Pacific J Clin Nutr 12: $151-160$

Kelly RB (2010) Diet and exercise in the management of hyperlipidemia. Am Fam Physician 81: 1097-1102

Khaw K, Sharp SJ, Finikarides L, Afza I, Lentjes M, Luben R, Forouhi NG (2018) Randomised trial of coconut oil, olive oil or butter on blood lipids and other cardiovascular risk factors in healthy men and women. BMJ Open 8: e020167. https://doi.org/10.1136/bmjopen-2017-020167

Kilkenny MF, Dunstan L, Busingye D, Purvis T, Reyneke M, Orgill M, Cadilhac DA (2017) Knowledge of risk factors for diabetes or cardiovascular disease (CVD) is poor among individuals with risk factors for CVD. PLOS ONE 12: e0172941. https://doi.org/10.1371/ journal.pone.0172941

Kirwan JP, Malin SK, Scelsi AR, Kullman El, Navaneethan SD, Pagadala MR, Haus JM, Filion J, Godin JP, Kochhar S, Ross AB (2016) A whole-grain diet reduces cardiovascular risk factors in overweight and obese adults: a randomized controlled trial. I Nutr 146: 2244-2251. https://doi.org/10.3945/in.116.230508

Knoops KTB, De Groot LCPGM, Kromhout D, Perrin AE, MoreirasVarela O, Menotti A, Van Staveren WA (2004) Mediterranean diet, lifestyle factors, and 10-year mortality in elderly european men and women: The HALE project. $J A M A$ 292: 1433-1439. https://doi. org/10.1001/jama.292.12.1433

Kopp W (2019) How western diet and lifestyle drive the pandemic of obesity and civilization diseases. Diabetes Metab Syndr Obes 12: 22212236. https://doi.org/10.2147/DMSO.S216791

Leslie MA, Cohen DJ, Liddle DM, Perrin AE, Moreiras-Varela O, Menotti A, Van Staveren WA (2015) A review of the effect of omega-3 polyunsaturated fatty acids on blood triacylglycerol levels in normolipidemic and borderline hyperlipidemic individuals. Lipids Health Dis 14: 53. https://doi.org/10.1186/s12944-015-0049-7

Li H, Zhang Q, Song J, Wang A, Zou Y, Ding L, Wen Y (2017) Plasma trans-fatty acids levels and mortality: a cohort study based on 1999-2000 National Health and Nutrition Examination Survey (NHANES). Lipids Health Dis 16: 176. https://doi.org/10.1186/ s12944-017-0567-6

Lordan R, Tsoupras A, Mitra B, Zabetakis I (2018) Dairy fats and cardiovascular disease: do we really need to be concerned? Foods 7: 29. https://doi.org/10.3390/ foods 7030029

Ma J, Li H (2018) The role of gut microbiota in atherosclerosis and hypertension. Front Pharmacol 9: 1082. https://doi.org/10.3389/ fphar.2018.01082

Mach F, Baigent C, Catapano AL, Koskinas KC, Casula M, Badimon L, Chapman MJ, De Backer GG, Delgado V, Ference BA, Graham IM, Halliday A, Landmesser U, Mihaylova B, Pedersen TR, Riccardi G, Richter DJ, Sabatine MS, Taskinen MR, Tokgozoglu L, Wiklund O; ESC Scientific Document Group. 2019 ESC/EAS Guidelines for the management of dyslipidaemias (2019): Lipid modification to reduce cardiovascular risk: The Task Force for the management of dyslipidaemias of the European Society of Cardiology (ESC) and European Atherosclerosis Society (EAS) Eur Heart J 41: 111-188. https://doi.org/10.1093/eurheartj/ehz455

Maćkowiak K, Torlińska-Walkowiak N, Torlińska B (2016) Dietary fibre as an important constituent of the diet. Postepy Hig Med Dosw 25: 104-109. https://doi.org/10.5604/17322693.1195842

Maki KC, Hasse W, Dicklin MR, Bell M, Buggia MA, Cassens ME, Eren F (2018) Corn oil lowers plasma cholesterol compared with coconut oil in adults with above-desirable levels of cholesterol in a randomized crossover trial. J Nutr 148: 1556-1563. https://doi. org/10.1093/jn/nxy156

Makki K, Deehan EC, Walter J, Bell M, Buggia MA, Cassens ME, Eren F (2018) The impact of dietary fiber on gut microbiota in host health and disease. Cell Host Microbe 23: 705-715. https://doi. org/10.1016/j.chom.2018.05.012

Malina DM, Fonseca FA, Barbosa SA, Kasmas SH, Machado VA, França CN, Borges NC, Moreno RA, Izar MC (2015) Additive effects of plant sterols supplementation in addition to different lipid-lowering regimens. J Clin Lipidol 9: 542-552. https://doi. org/10.1016/i.jacl.2015.04.003

Mani I, Kurpad AV (2016) Fats \& fatty acids in Indian diets: Time for serious introspection. Indian J Med Res 144: 507-514. https:// doi.org/10.4103/0971-5916.200904

Mann S, Beedie C, Jimenez A (2014) Differential effects of aerobic exercise, resistance training and combined exercise modalities on cholesterol and the lipid profile: review, synthesis and recommendations. Sports Med 44: 211-221. https://doi.org/10.1007/s40279-0130110-5 
Mannu GS, Zaman MJ, Gupta A, Rehman HU, Myint PK (2013) Evidence of lifestyle modification in the management of hypercholesterolemia. Curr Cardiol Rev 9: 2-14. https://doi. org/10.2174/157340313805076313

Matsumoto S, Beeson WL, Shavlik DJ, Siapco G, Jaceldo-Siegl K, Fraser G, Knutsen SF (2019) Association between vegetarian diets and cardiovascular risk factors in non-Hispanic white participants of the Adventist Health Study-2. J Nutr Sci 8: e6. https://doi. org/10.1017/jns.2019.1

McRae MP (2017) Dietary fiber is beneficial for the prevention of cardiovascular disease: an umbrella review of meta-analyses. J Chiropr Med 16: 289-299. https://doi.org/10.1016/j.jcm.2017.05.005

Michas G, Karvelas G, Trikas A (2019) Cardiovascular disease in Greece; the latest evidence on risk factors. Hellenic J Cardiol 60: 271275. https://doi.org/10.1016/j.hjc.2018.09.006

Misra R, Balagopal P, Raj S, Patel TG (2018) Patel Vegetarian Diet and Cardiometabolic Risk among Asian Indians in the United States. J Diabetes Res 2018: 1675369. https://doi.org/10.1155/2018/1675369

$\mathrm{Na}$ YM, Park HA, Kang JH, Cho YG, Kim KW, Hur YI, Kim YN, Lee SH (2011) Obesity, obesity related disease, and disability. Korean J Fam Med 32: 412-422. https:// doi.org/10.4082/kjfm.2011.32.7.412

Nebl J, Schuchardt JP, Wasserfurth P, Haufe S, Eigendorf J, Tegtbur U, Hahn A (2019) Characterization, dietary habits and nutritional intake of omnivorous, lacto-ovo vegetarian and vegan runners - a pilot study. BMC Nutr 5: 51. https://doi.org/10.1186/s40795-0190313-8

Nettleton JA, Brouwer IA, Geleijnse JM, Hornstra G (2017) Saturated fat consumption and risk of coronary heart disease and ischemic stroke: a science update. Ann Nutr Metab 70: 26-33. https://doi. org/10.1159/000455681

Ng TW, Watts GF, Barrett PH, Rye KA, Chan DC (2007) Effect of weight loss on LDL and HDL kinetics in the metabolic syndrome. Diabetes Care 30: 2945-2950. https://doi.org/10.2337/dc07-0768

Okami Y, Ueshima H, Nakamura Y, Okuda N, Nakagawa H, Sakata K, Saitoh S, Okayama A, Yoshita K, Choudhury SR, Chan Q, Elliott P, Stamler J, Miura K (2019) The relationship of dietary cholesterol with serum low-density lipoprotein cholesterol and confounding by reverse causality: The INTERLIPID study. I Atheroscler Thromb 26: 170-182. https://doi.org/10.5551/jat.43075

Oliveira-de-Lira L, Santos EMC, de Souza RF, Barbosa Matos RJ, Cesiana da Silva M, Dos Santos Oliveira L, Galdêncio do Nascimento T, De Lara Schinda Schemly PA, Lopes de Souza S (2018) Supplementation-dependent effects of vegetable oils with varying fatty acid compositions on anthropometric and biochemical parameters in obese women. Nutrients 10: 932. https://doi.org/10.3390/ nu10070932

O’Sullivan TA, Hafekost K, Mitrou F, Lawrence D (2013) Food sources of saturated fat and the association with mortality: a metaanalysis. Am J Public Health 103: e31-e42. https://doi.org/10.2105/ AJPH.2013.301492

Ottestad I, Ose L, Wennersberg MH, Granlund L, Kirkhus B, Retterstøl K (2013) Phytosterol capsules and serum cholesterol in hypercholesterolemia: a randomized controlled trial. Atherosclerosis 228: 421-425. https://doi.org/10.1016/j.atherosclerosis.2013.03.001

Pimpin L, Wu JH, Haskelberg H, Del Gobbo L, Mozaffarian D (2016) Is butter back? a systematic review and meta-analysis of butter consumption and risk of cardiovascular disease, diabetes, and total mortality. PLoS One 11: e0158118. https://doi.org/10.1371/journal. pone. 0158118

Poli A, Barbagallo CM, Cicero AFG, Corsini A, Manzato E, Trimarco B, Bernini F, Visioli F, Bianchi A, Canzone G, Crescini C, De Kreutzenberg S, NFerrara N, Gambacciani M, Ghiselli A, Lubrano C, Marelli G, Marrocco W, Montemurro V, Parretti D, Pedretti R, Perticone F, Stella R, Marangoni F (2018) Nutraceuticals and functional foods for the control of plasma cholesterol levels. An intersociety position paper. Pharmacol Res 134: 51-60. https://doi. org/10.1016/j.phrs.2018.05.015

Riccardi G, Vaccaro O, Costabile G, Rivellese AA (2016) How well can we control dyslipidemias through lifestyle modifications? Curr Cardiol Rep 18: 66. https://doi.org/10.1007/s11886-016-0744-7

Rogerson D (2017) Vegan diets: practical advice for athletes and exercisers. J Int Soc Sports Nutr 14: 36. https://doi.org/10.1186/s12970017-0192-9

Romero-Moraleda B, Peinado Lozano AB, Morencos Martínez E (2015) Lipid profile response to weight loss program in overweight and obese patient is related with gender and age. Nutr Hosp 31: 2455-2464. https://doi.org/10.3305/nh.2015.31.6.8926

Sanclemente T, Marques-Lopes I, Fajó-Pascual M, Cofán M, Jarauta E, Ros E, Puzo J, García-Otín AL (2012) Naturally-occurring phytosterols in the usual diet influence cholesterol metabolism in healthy subjects. Nutr Metab Cardiovasc Dis 22: 849-855. https://doi. org/10.1016/j.numecd.2011.01.010
Savji N, Rockman CB, Skolnick AH, Guo Y, Adelman MA, Riles T, Berger JS (2013) Association between advanced age and vascular disease in different arterial territories: a population database of over 3.6 million subjects. I Am Coll Cardiol 61: 1736-1743. https://doi. org/10.1016/j.jacc.2013.01.054

Schönfeld P, Wojtczak L (2016) Short- and medium-chain fatty acids in energy metabolism: the cellular perspective. I Lipid Res 57: 943954. https://doi.org/10.1194/ilr.R067629

Shah B, Newman JD, Woolf K, Ganguzza L, Guo Y, Allen N, Zhong J, Fisher EA, Slater J (2018) Anti-inflammatory effects of a vegan diet versus the american heart association-recommended diet in coronary artery disease trial. I Am Heart Assoc 7: e011367. https://doi. org/10.1161/JAHA.118.011367

Shahidi F, Ambigaipalan P (2018) Omega-3 polyunsaturated fatty acids and their health benefits. Annu Rev Food Sci Technol 9: 345-381. https://doi.org/10.1146/annurev-food-111317-095850

Sofi F, Dinu M, Pagliai G, Cesari F, Gori AM, Sereni A, Becatti M, Fiorillo C, Marcucci R, Casini A (2018) Low-calorie vegetarian versus mediterranean diets for reducing body weight and improving cardiovascular risk profile: CARDIVEG study (Cardiovascular Prevention With Vegetarian Diet). Circulation 137: 1103-1113. https:// doi.org/10.1161/CIRCULATIONAHA.117.030088

Solà R, Bruckert E, Valls RM, Narejos S, Luque X, Castro-Cabezas M, Doménech G, Torres F, Heras M, Farrés X, Vaquer JV, Martínez JM, Almaraz MC, Anguera A (2010) Soluble fibre (Plantago ovata husk) reduces plasma low-density lipoprotein (LDL) cholesterol, triglycerides, insulin, oxidised LDL and systolic blood pressure in hypercholesterolaemic patients: A randomised trial. Atherosclerosis 211: 630-637. https://doi.org/10.1016/i.atherosclerosis.2010.03.010

Sosnowska B, Penson P, Banach M (2017) The role of nutraceuticals in the prevention of cardiovascular disease. Cardiovasc Diagn Ther 7: S21-S31. https://doi.org/10.21037/cdt.2017.03.20

Stewart J, Manmathan G, Wilkinson P (2017) Primary prevention of cardiovascular disease: A review of contemporary guidance and literature. JRSM Cardiovasc Dis 6: 1-9. https:/\% doi. org $/ 10.1177 / 2048004016687211$

Tong TYN, Appleby PN, Bradbury KE, Perez-Cornago A, Travis RC, Clarke R, Key TJ (2019) Risks of ischaemic heart disease and stroke in meat eaters, fish eaters, and vegetarians over 18 years of followup: results from the prospective EPIC-Oxford study. BMJ 366: 14897. https://doi.org/10.1136/bmj.14897

Trichopoulou A, Martínez-González MA, Tong TY, Forouhi NG, Khandelwal S, Prabhakaran D, Mozaffarian D, De Lorgeril M (2014) Definitions and potential health benefits of the Mediterranean diet: views from experts around the world. BMC Med 12: 112. https://doi.org/10.1186/1741-7015-12-112

U.S. Department of Agriculture (2019) Agricultural Research Service. FoodData Central.

Viguiliouk E, Kendall CW, Kahleová H, Rahelić D, Salas-Salvadó J, Choo VL, Blanco Mejia S, Stewart SE, Leiter LA, Jenkins DJ, Sievenpiper JL (2019) Effect of vegetarian dietary patterns on cardiometabolic risk factors in diabetes: A systematic review and metaanalysis of randomized controlled trials. Clin Nutr 38: 1133-1145. https://doi.org/10.1016/j.clnu.2018.05.032

Vijayakumar M, Vasudevan DM, Sundaram KR, Krishnan S, Vaidyanathan K, Nandakumar S, Chandrasekhar R, Mathew N (2016) A randomized study of coconut oil versus sunflower oil on cardiovascular risk factors in patients with stable coronary heart disease. Indian Heart J 68: 498-506. https://doi.org/10.1016/j.ihj.2015.10.384

Visioli F, Poli A (2019) Prevention and treatment of atherosclerosis: the use of nutraceuticals and functional foods. In: Handbook of Experimental Pharmacology, p. 1-15

Vitiello V, Germani A, Capuzzo Dolcetta E, Donini LM, Del Balzo V (2016) The New Modern Mediterranean Diet Italian Pyramid. Ann Ig 28: 179-186. https://doi.org/10.7416/ai.2016.2096

Von Ruesten, A, Feller S, Bergmann M, Boeing H (2013) Diet and risk of chronic diseases: results from the first 8 years of follow-up in the EPIC-Potsdam study. Eur J Clin Nutr 67: 412-419. https://doi. org/10.1038/ejcn.2013.7

Zhang M, Juraschek SP, Appel LJ, Pasricha PJ, Miller ER, Mueller NT (2020) Effects of high-fiber diets and macronutrient substitution on bloating: findings from the OmniHeart Trial. Clin Transl Gastroenterol 11: e00122. https://doi.org/10.14309/ctg.0000000000000122

Zhong VW, Van Horn L, Cornelis MC, Wilkins JT, Ning H, Carnethon MR, Greenland P, Mentz RJ, Tucker KL, Zhao L, Norwood AF, Lloyd-Jones DM, Allen NB (2019) Associations of dietary cholesterol or egg consumption with incident cardiovascular disease and mortality. JAMA 321: 1081-1095. https://doi.org/10.1001/ jama.2019.1572 